\title{
Pain threshold, sleep quality and anxiety levels in individuals with temporomandibular disorders
}

\author{
Carla Raquel de Melo Daher(") \\ Larissa Fernandes da Cunha ${ }^{(1)}$ \\ Ana Paula de Lima Ferreira(1) \\ Ana Izabela Sobral de Oliveira Souza ${ }^{(1)}$ \\ Tiago Albuquerque Maranhão Rêgo (1) \\ Maria das Graças Rodrigues de Araújo(1) \\ Hilton Justino da Silva ${ }^{(1)}$
}

1) Universidade Federal de Pernambuco, Centro de Ciências da Saúde, Recife, Pernambuco, Brasil.

Study performed at the Laboratório de Motricidade Oral do Departamento de Fonoaudiologia and at the Laboratório de Cinesioterapia e Recursos Terapêuticos Manuais (LACIRTEM) do Departamento de Fisioterapia da Universidade Federal de Pernambuco, Brasil.

Research support source: Program of Scientific Initiation Scholarships of Universidade Federal de Pernambuco PIBIC / UFPE / CNPq.

Conflict of interests: Nonexistent

\section{(c) (i)}

Received on: September 20, 2017 Accepted on: May 6, 2018

Corresponding author: Larissa Fernandes da Cunha Rua Arquiteto Luis Nunes, 1263. Apt 202 CEP: $51170-430$ - Imbiribeira, Recife, Pernambuco, Brasil

E-mail: fc.larissa17@gmail.com

\section{ABSTRACT}

Purpose: to evaluate the pressure pain threshold, sleep quality and anxiety levels of individuals with different types of chronic temporomandibular disorders (TMD).

Methods: a controlled, observational and cross-sectional study. TMD diagnosis followed the Research Diagnostic Criteria and the volunteers were divided into three groups: A-Muscular Disorder $(n=15)$, B- Articular Disorder $(n=10)$ and C- Control Group $(n=15)$. Evaluation was performed using the Pittsburg Sleep Quality Index, Visual Analog Scale, Algometry and Hospital Anxiety and Depression Scale. The significance level for all tests was $5 \%$.

Results: lower threshold of pain was seen in the masticatory and cervical musculature within groups $A$ and $B$. However, when TMD groups were compared to the control group, only a statistically significant difference in the pain threshold of the masticatory muscle and the trapezius muscle was found. Groups A and B presented poor sleep quality, showing a statistical difference when compared to the control group. Additionally, it was observed that patients in the groups with TMD presented anxiety, while those in the control group, did not present it.

Conclusion: individuals presented with TMD show lower levels of pain threshold, sleep quality and anxiety, as compared to healthy subjects. These results do not depend on the type of disorder presented.

Keywords: Temporomandibular Joint Disorder; Pain; Sleep; Anxiety 


\section{INTRODUCTION}

According to the Academy of Orofacial Pain, the temporomandibular disorder (TMD) is a set of disorders involving the masticatory muscles, temporomandibular joint (TMJ) and associated structures. The TMD is recognized as the main cause of non-dental pain in the orofacial region and negatively affects oral function and quality of life of the general population'. It affects five women for each man $(5: 1)$ in all age groups, although it is more common in individuals between 20 and 45 years $^{2}$. The TMD may have a muscular or joint onset ${ }^{2}$. The most frequent symptoms reported by the patients involve muscle fatigue, articular noise, headache, limitation and/or deviations of jaw movements, and facial pain ${ }^{2-4}$. When the pain reported by the patient lasts longer than three months, it is stated that the person has Chronic Temporomandibular Joint Disorder.

Pain is an unpleasant sensory and emotional experience associated with a real or potential tissue damage, and a multidimensional characteristic. During pain evaluation, not only the physical and chemical components but also the subjective and psychological aspects can be considered, mainly in patients with chronic pain ${ }^{5}$. Within this same context, it is known that individuals with chronic pain, in addition to pain often exhibit oscillations in their emotional behavior and sleep disturbances.

Sleep disturbances may reflect a waking state at night, resulting in a non-restorative sleep sensation, psychological stress, and chronic fatigue ${ }^{6,7}$. According to other studies report, there is a significant association between the variables pain, anxiety and depression with changes in sleep quality ${ }^{6,7}$. Many individuals with TMD report complaints about poor sleep quality and anxiety; however, it is not known if these symptoms are associated with TMD type ${ }^{7-9}$. In addition to the poor quality of sleep presented by the patients with TMD, a high pain sensitivity has been observed. Nonetheless, the casual relationship of these events presents many biases $^{10,11}$.

Mental disorders such as anxiety, depression and stress are often observed in individuals with TMD ${ }^{12-15}$. Moreover, it is possible to define chronic TMD as a disease in which may be associated to psychological factors ${ }^{14}$. Anxiety makes the subject hypervigilant to pain causing amplification of nociceptive sensitivity ${ }^{16}$.

Considering all gaps existing in pain threshold levels, sleep quality, and anxiety levels of individuals with different types of temporomandibular disorders, the aim of this study was to evaluate pain threshold, sleep quality, and anxiety levels among healthy individuals and with different types of TMD.

\section{METHODS}

The present study was approved by the Ethics Committee of the Universidade Federal de Pernambuco - UFPE, according to Resolution 466/12 of the National Health Council which deals with the Code of Ethics for research on human beings, under registration $\mathrm{CAAE}$ 44109715.9.0000.5208. The purpose of the research was clarified for the volunteer and then signed the Free and Informed Consent Term (TCLE).

It is a controlled, observational and cross-sectional study. The sample was constituted by criterion of convenience. The volunteers were selected by spontaneous demand and through the dissemination of this research in social networks. Data collection was performed at the Laboratory of Kinesiotherapy and Manual Therapeutic Resources of the Department of Physical Therapy, and at the Laboratory of Orofacial Motricity, both at UFPE. Data collection started in June/2016 and was completed in January/2017.

As inclusion criteria, volunteers of both genders and age between 18 and 45 years, with TMD and painful sensation for at least 3 months of persistence. For individuals in the control group, those with similar age groups without complaints of pain and without TMD were included. The TMD in both groups was verified by the physical examination of the Research Diagnostic Criteria (RDC). RDC has been considered the gold standard physical examination for clinical diagnosis of TMD. It may or may not be supplemented with electrophysiological and imaging tests, procedures not used in this study. In all study groups, individuals with a history of facial trauma, rheumatic and orthopedic pathologies, surgical procedures performed in the cranio-cervical region and neurological diseases, individuals who were using any type of medicine and/or orthodontic/ orthopedic functional appliance at the moment of data collection were excluded. For females, those who were in the menstrual period were also excluded.

Two evaluators, one being responsible for collecting the data and applying the exams and questionnaires, carried out this research. The other evaluator performed the scores calculation of the evaluations. First, the anamnesis of the individuals was made, then the questionnaires were applied, and finally the algometry and the Visual Analog Scale (EVA) were performed.

The diagnosis of Temporomandibular Disorder was performed by an experienced and qualified evaluator, 
according to the criteria of the Research Diagnostic Criteria developed ${ }^{17}$, translated and validated in Brazil ${ }^{18}$. For these criteria, individuals with muscular TMD of the subgroups were: la (myofascial pain without limited buccal opening) or lb (myofascial pain with limited buccal opening) and individuals with joint TMD of the subgroups: IIA (displacement of disc with reduction) or IIB (displacement of disc without reduction and without opening limit).

The Visual Analog Scale (VAS) of pain was used to assess pain ${ }^{19}$. The VAS quantifies the pain experience in a single dimension using a straight line of $100 \mathrm{~mm}$, with the left margin anchored by face expression without pain and another corresponding to the worst pain imaginable, without the millimeter values being visible to the patient (Figure 1).

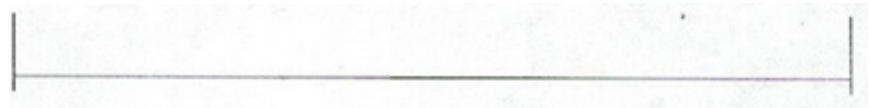

No pain

Pain as bad as it

Source: Jensen, Karoly and Brauer (1986). could possibly be

Figure 1. Visual Analog Scale

The volunteer was requested to mark a vertical line at the point that represents the intensity of the pain felt. Subsequently, a blind evaluator measured the distance between the end anchored by the expression without pain and the mark made by the volunteer, which corresponded to the intensity of his/her pain, in millimeters.

In the algometry examination, the pressure pain threshold was verified using a Wagner ${ }^{\circledR}$ digital algometer, model FDX, with accuracy of $0.3 \%$ (Figure 2).

In the algometry examination, the masticatory and cervical muscles (masseter, temporal, sternocleidomastoid 'SCM' and trapezius, bilaterally) were examined in addition to the lateral pole of the mandible (joint point of TMJ), using AMERICAN SLEEP DISORDERS ASSOCIATION criteria. The algometer tip was positioned in the studied muscles until the individual described the pain. The value demonstrated by the algometer was considered as pain threshold.

As recommended by the Research Diagnostic Criteria, reports of familial pain (i.e. reproductive spontaneous pain during crisis) were considered clinically significant at palpatory examination, with value equal to or less than: $1 \mathrm{~kg}$ for anterior temporal and masseter,

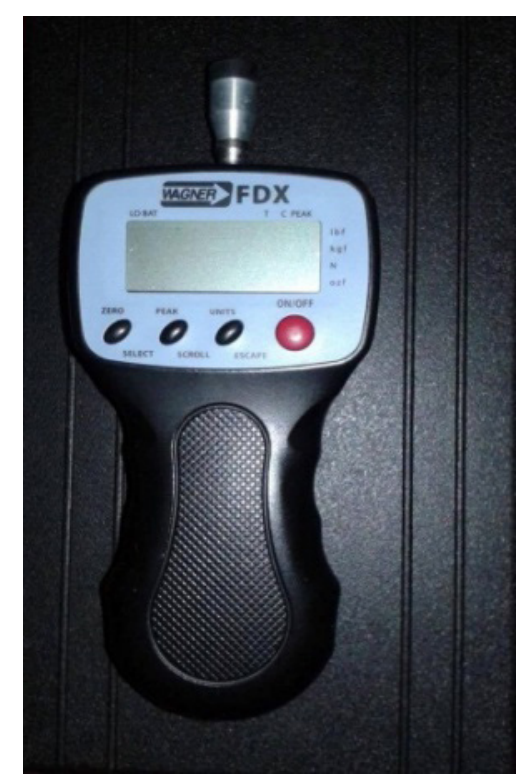

Source: Register made during the research period.

Figure 2. Algometer

500 grams for the lateral pole of the mandible and $2 \mathrm{Kg}$ for SCM and trapezium.

To evaluate sleep quality, the Pittsburgh Sleep Quality Index (PSQI) ${ }^{20}$ was used as the criterion for assessing sleep quality in the last month, providing the severity index and the nature of the disorder. The Pittsburgh Sleep Quality questionnaire was validated for Portuguese language ${ }^{21}$ and has been shown to be an important tool to correlate with other variables in the study, such as pain and TMD. Score less than or equal to 5 means optimum sleep quality and greater or equal to 6 equals poor sleep quality.

Anxiety was evaluated by the Hospital Anxiety and Depression Scale (HADS) ${ }^{22}$. This scale has been widely used by health professionals and has proved to be a good tool to be used. HADS consists of 14 items, 7 of which are for anxiety assessment (HADS-A) and the other 7 for depression (HADS-D). Each item can be punctuated from 0 to 3 points, being able to reach 21 points each scale. From 0 to 7 points is unlikely, from 8 to 11 is possible, however it is doubtful, and above 12 is likely.

The program used to make the statistics was BioEstat 5.0. For the analysis of the normality of the data the Shapiro Wilk test was used. To characterize the sample, a descriptive analysis was performed using mean and standard deviation for the continuous variables and frequency for categorical variables. To assess differences between groups at baseline, unpaired $\mathrm{t}$ test for continuous variables was used. 
To compare the variables VAS, algometry, sleep quality and anxiety intergroups was used two-way ANOVA followed by the Tukey test post. Values were presented on average $(\mathrm{X})$, standard deviation (SD) and percentages (\%). The significance level for all tests was $5 \%$. It should be noted that the statistical evaluation was performed by a blind researcher not involved in the patients' evaluations.

\section{RESULTS}

The results of the study flow can be seen in Figure 3.

The general characteristics of the sample are set forth in Table 1.

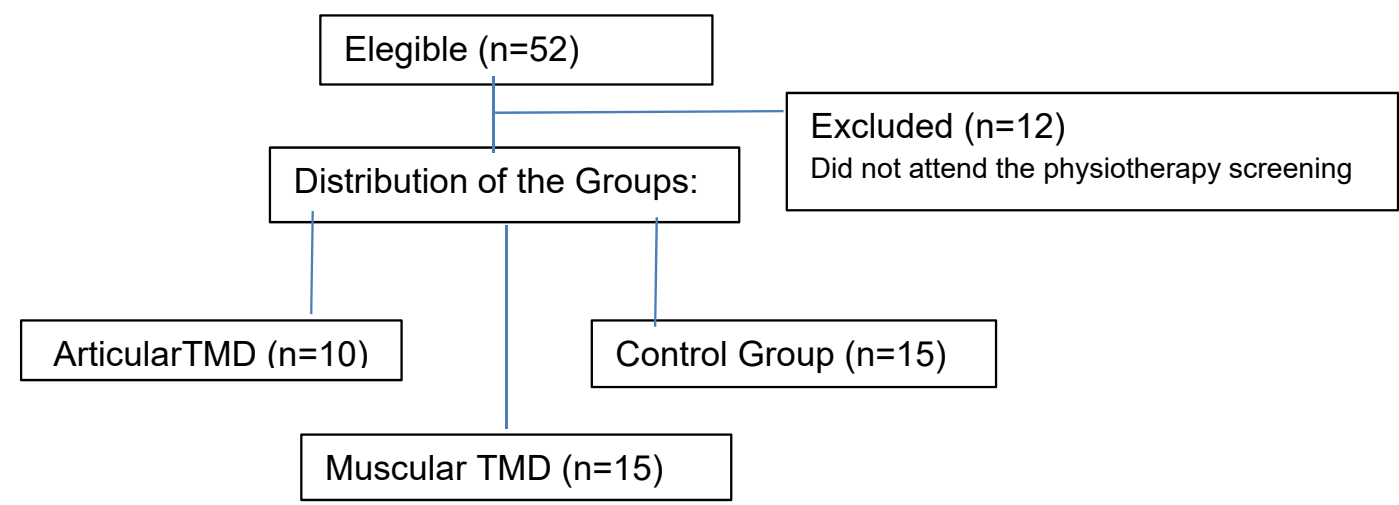

Legend: TMD $=$ Temporomandibular Disorder

Figure 3. Flow of volunteers during the research

Table 1. General summary of the sample characteristics

\begin{tabular}{cccc}
\hline Variables & $\begin{array}{c}\text { GROUP A } \\
\text { Articular TMD } \\
(\mathbf{n}=\mathbf{1 0})\end{array}$ & $\begin{array}{c}\text { GROUP B } \\
\text { Muscular TMD } \\
(\mathbf{n}=15)\end{array}$ & $\begin{array}{c}\text { GROUP C } \\
\text { Control } \\
(\mathbf{n}=15)\end{array}$ \\
\hline Gender $(\mathbf{n})$ & & & \\
Females & $8(80 \%)$ & $11(73.3 \%)$ & $12(80 \%)$ \\
Males & $2(20 \%)$ & $4(26.6 \%)$ & $3(20 \%)$ \\
\hline Age (years) & $24.15 \pm 3.01^{\mathrm{A}}$ & $25.10 \pm 3.87^{\mathrm{A}}$ & $23.15 \pm 3.65^{\mathrm{A}}$ \\
\hline Body Mass Index $\left(\mathrm{kg} / \mathrm{m}^{2}\right)$ & $23.29 \pm 2.28^{\mathrm{A}}$ & $24.45 \pm 5.80^{\mathrm{A}}$ & $23.49 \pm 1.98^{\mathrm{A}}$ \\
\hline
\end{tabular}

Capital letters at the same line mean that there is no intergroup difference. $T$ test was not matched $(p<0,05)$.

Legend: TMD $=$ Temporomandibular Disorder

As shown in Table 2, the pain referred to in the visual analog scale did not present statistically significant differences between the groups with articular and muscular TMD. However, lower pain threshold values were observed in the masticatory and trapezius muscles of individuals with muscle and joint TMD when compared to the control group.
Table 3 shows that individuals with joint and muscular TMD have worse quality of sleep and anxiety scores when compared to individuals in the control group. 
Table 2. Average (standard-deviation) of the values of the Visual Analog Scale (VAS), Algometry (pressure pain threshold in Kgf/cm2) of the masticatory musculature, TMJ lateral pole and cervical muscle among individuals with different types of temporomandibular disorder and the control group

\begin{tabular}{cccc}
\hline Variables & $\begin{array}{c}\text { GROUP A } \\
\text { Articular TMD } \\
(\mathbf{n}=\mathbf{1 0})\end{array}$ & $\begin{array}{c}\text { GROUP B } \\
\text { Muscular TMD } \\
(\mathbf{n}=15)\end{array}$ & $\begin{array}{c}\text { GROUP C } \\
\text { Control } \\
\mathbf{( n = 1 5 )}\end{array}$ \\
\hline VAS & $61.5 \pm 12.85^{\mathrm{A}}$ & $59.5 \pm 16.19^{\mathrm{A}}$ & \\
\hline ALGOMETRY & & & \\
Masseter & $1.69(0.74)^{\mathrm{A}}$ & $1.62(0.62)^{\mathrm{A}}$ & $3.71(0.67)^{\mathrm{B}}$ \\
Anterior Temporal & $1.83(0.80)^{\mathrm{A}}$ & $1.52(0.88)^{\mathrm{A}}$ & $2.89(0.92)^{\mathrm{B}}$ \\
TMJ Lateral Pole & $1.04(0.31)^{\mathrm{A}}$ & $2.01(0.47)^{\mathrm{B}}$ & $3.66(0.41)^{\mathrm{C}}$ \\
Sternocleidomastoid & $1.32(0.45)^{\mathrm{A}}$ & $1.46(0.58)^{\mathrm{A}}$ & $1.49(0.64)^{\mathrm{A}}$ \\
Trapezius & $1.61(0.85)^{\mathrm{A}}$ & $1.77(0.94)^{\mathrm{A}}$ & $2.69(1.09)^{\mathrm{B}}$ \\
\hline
\end{tabular}

Capital letters at the same line mean that there is an intergroup difference.

Two-way ANOVA followed by Tukey's post-test $(p<0,05)$.

Legend: TMD $=$ Temporomandibular Disorder

Table 3. Average (standard - deviation) of the values of the sleep quality, anxiety levels among individuals with different types of temporomandibular disorder and the control group

\begin{tabular}{cccc}
\hline Variables & $\begin{array}{c}\text { GROUP A } \\
\text { Articular TMD } \\
(\mathbf{n}=10)\end{array}$ & $\begin{array}{c}\text { GROUP B } \\
\text { Muscular TMD } \\
(\mathbf{n}=15)\end{array}$ & $\begin{array}{c}\text { GROUP C } \\
\text { Control } \\
(\mathbf{n}=15)\end{array}$ \\
\hline Sleep Quality & $8.35 \pm 4.20^{\mathrm{A}}$ & $10.20 \pm 5.53^{\mathrm{A}}$ & $3.54 \pm 0.53^{\mathrm{B}}$ \\
Anxiety Levels & $15.38 \pm 2.42^{\mathrm{A}}$ & $16.85 \pm 2.02^{\mathrm{A}}$ & $1.03 \pm 0.72^{\mathrm{B}}$ \\
\hline
\end{tabular}

Capital letters at the same line mean that there is a difference intergroup.

Two-way ANOVA followed by Tukey's post-test $(p<0,05)$.

Legend: TMD $=$ Temporomandibular Disorder

\section{DISCUSSION}

The main findings of this study were: when compared to control, individuals with TMD present lower pain thresholds; i.e., they support lower mechanical pressures exerted on the masticatory muscles, TMJ and cervical muscles triggering pain. In addition, they exhibit worse quality of sleep and anxiety. However, both groups with TMD showed changes in these variables with no significant difference between them. Only the sternocleidomastoid muscle presented pain threshold below the clinically expected in the three groups evaluated. Healthy individuals were expected to have no reduction in pain threshold. Moreover, it was not possible to relate this data to the individuals' head posture since posture was not a variable explored in the present study.

Another finding was that the females presented a higher prevalence of TMD, what agrees with the results of other studies performed in different populations ${ }^{4,23,24}$. Probably, this higher prevalence is related to hormonal variations, especially estrogen, since there is already evidence that sex hormones increase the probability of having TMD by direct influence on collagen and elastin synthesis ${ }^{23-25}$.

In this study, pain levels were evaluated through VAS, as it is a practical, easy to use and universally used method to assess pain intensity. However, it is often realized that individuals have difficulty objectifying the intensity of pain through a numerical data or a scale. In addition, one-dimensional scales provide little information on the physical characteristics of pain and frequently, the value indicated by the patient reflects the emotional profile of the painful experience ${ }^{26}$. It was therefore necessary to evaluate pain also by the algometry that provides the quantitative measure of pain through a mechanical experience ${ }^{27}$. When using VAS and algometry in this study, it was observed that there was no statistical difference between the TMD groups in relation to pain sensitivity, except for the lateral pole. However, when considering the difference of clinically important pain of all the pain sites analyzed, only the trapezius muscle presented a below-expected 
difference $(2 \mathrm{~kg} / \mathrm{F})$ in the TMD groups in relation to the control. These findings reveal that although individuals with TMD have less resistance to painful stimuli when compared to individuals without TMD, their pain levels were not potentially important to show a significant clinical difference. This fact probably reflects an adaptability to the condition of chronic pain, which can be investigated in future studies.

The lower muscle pain thresholds observed in those with TMD from this study corroborate with the findings of another study ${ }^{28}$, which also showed that individuals with TMD have a lower pain threshold compared to healthy individuals ${ }^{28}$. When it comes to patients with chronic pain, it is known that the increase of pain sensitivity in diverse sites is caused by prolonged nociceptive stimuli of the myofascial tissue that sensitize the central nervous system. Neuronal hyperexcitability results from changes that can alter from the level of the peripheral receptors to the higher sensory centers of the brain. In this way, nociceptive impulses would be responsible for the elevation of pain sensitivity and the reduction of the multifocal pain threshold (muscular and articular) 29-31.

In the same way that the muscular pain sensitivity did not differ between the TMD groups, the anxiety also presented the same picture. It can be inferred that it is not the type of TMD, but the existence of chronic pain that is closely related to anxiety ${ }^{32,33}$. Anxiety may contribute to the process of sensitization and hyperalgesia in chronic patients, which leads to an increase in the memory of pain and anticipation of pain sensations $^{34,35}$. In a literature review study, Chisnoiu ${ }^{36}$ observed that stress, anxiety, and psychological factors induce muscle hyperactivity and muscle fatigue resulting in contracture, occlusal disharmony, and internal TMJ disorders.

It is worth noting that anxiety alone does not trigger TMD, but acts as a predisposing or aggravating factor $^{8,16}$. In the present study, anxiety was evaluated by HADS because it was a questionnaire of rapid application, making it feasible to use within the methodology that was drawn. However, anxiety specificities are not possible to be measured by this instrument. Unlike the IDATE Questionnaire that quantifies anxious traits and states. Oliveira ${ }^{8}$ using the IDATE identified that traits of anxiety (personality trait) correlates with the presence of TMD, confirming its etiological role. On the other hand, anxiety state (anxiety reactions to stress situations) correlates positively with the severity of $\mathrm{TMD}^{8}$. The presence of psychosocial factors, such as anxiety and sleep problems, may act as chronicity factors for TMD and cause pain amplification ${ }^{37}$.

The poor sleep quality identified in this study corroborates with Luro $^{38}$. Patients with sleep disturbances have an increased pain perception, which is related to the intensity of high pain in patients with chronic pain ${ }^{36}$. However, the causal relationship between poor sleep quality and temporomandibular disorder is unknown, that is, whether it is chronic pain that produces sleep disorder or whether sleep disturbance is a significant factor for the onset of chronic pain ${ }^{39}$. In a study of 54 individuals with TMD, it was observed that those with better sleep quality had greater control over the mechanism of endogenous modulation. Thus, it was verified that individuals with TMD and sleep disorders have less inhibitory control of pain ${ }^{40}$.

Limitations of this research: (1) the sample was not constituted by a typical population, that is, the one that goes to the outpatient clinic for the treatment of TMD pain; (2) the Anxiety Questionnaire used (HADS) does not characterize specificities regarding traits and anxiety states; (3) low number of participants considering the high prevalence of the disorders analyzed (muscular and articular TMD).

The results presented in this study may lead to the reflection of the presence of pain in different types of TMD and consequently to the study of ways of treating. The presence of symptoms related to sleep may also contribute to the future establishment of relationships with pain in TMD.

\section{CONCLUSION}

When compared to healthy people, individuals with chronic TMD have lower levels of pain threshold. In addition, they present higher levels of anxiety and lower quality of sleep. These results do not depend on the type of disorder.

\section{ACKNOWLEDGMENT}

Thanks to the Institutional Program of Scientific Initiation Scholarships of Universidade Federal de Pernambuco - PIBIC / UFPE / CNPq for the grant of Scientific Initiation Research.

\section{REFERENCES}

1. Giro G, Policastro VB, Scavassin PM, Leite ARP, Mendoza Marin DO, Gonçalves DA et al. Mandibular kinesiographic pattern of women with chronic TMD after management with educational and self-care 
therapies: a double-blind, randomized clinical trial. J Prosthet Dent. 2016;116(5):749-55.

2. Dantas AM, Santos EJ, Vilela RM, Lucena LB. Perfil epidemiológico de pacientes atendidos em um serviço de controle da dor orofacial. Rev Odontologia UNESP. 2015;44(6):313-9.

3. Garbelotti TO, Turci AM, Serigato JM, Pizzol K, Franco-Micheloni AL. Effectiveness of acupuncture for temporomandibular disorders and associated symptoms. Rev Dor. 2016;17(3):223-7.

4. Donnarumma MC, Muzilli CA, Ferreira C, Nemr K. Temporomandibular Disorders: signs, symptoms and multidisciplinary approach. Rev. CEFAC. 2010;12(5):788-94.

5. Oliveira AS, Bermudez CC, Souza RA, Souza CM, Dias EM, Castro $C$ et al. Impacto da dor na vida de portadores de disfunção temporomandibular. J Appl Oral Sci. 2003;11(2):138-43.

6. Piccin CF. Clinical and psychosocial aspects assessed by the research diagnostic criteria for temporomandibular disorder. Rev. CEFAC. 2016;18(1):113-9.

7. Martins RJ, Garcia AR, Garbin CA, Sundefeld ML. Relação da classe econômica e qualidade do sono na ocorrência da disfunção temporomandibular. Rev Odontol da UCSP. 2008;20(2):147-53.

8. Oliveira LK, Almeida GA, Lelis ER, Tavares M, Fernandes Neto AJ. Temporomandibular disorder and anxiety, quality of sleep and quality of life in nursing professionals. Braz Oral Res. 2015;29(1):1-7.

9. Braga AC, Souza FL. Transtornos psicológicos associados à disfunção temporomandibular. Psicologia e Saúde em Debate. 2016;2(1):100-20.

10. Drabovicz PV, Salles V, Drabovicz PE, Fontes MJ. Assessment of sleep quality in adolescents whit temporomandibular disorders. Jornal de Pediatria. 2012;99(2):169-72.

11. Velly AM, Look JO, Carlson C, Lenton PA, Kang W, Holcroft CA et al. The effect of catastrophizing and depression on chronic pain - a prospective cohort study of temporomandibular muscle and joint pain disorders. Pain. 2011;152(10):2377-83.

12. Sartoretto SC, Dal Bello Y, Della Bona A. Evidências científicas para o diagnóstico e tratamento da DTM e a relação com a oclusão e a Ortodontia. RFO. 2012;17(3):352-9.

13. Schmidt DR, Ferreira VR, Wagner MF. Disfunção temporomandibular: sintomas de ansiedade, depressão e esquemas iniciais desadaptativos. Temas em Psicologia. 2015;23(4):4-13.

14. Dias da Silva AM. Relação entre a disfunção temporomandibular e os fatores psicossomáticos [Dissertação]. Viseu (Portugal): Universidade Católica Portuguesa; 2015.

15. Aggarwal VR, Lovell K, Peters S, Javadi H, Joughin A, Goldthorpe J. Psychosocial interventions for the management of chronic orofacial pain. Cochrane Database of Systematic Reviews. 2011;9(11):170.

16. Tournavitis A, Tortopidis D, Konstantinos F, Menexes G, Bmath MA, Koidis DD. Psychopathologic profiles of TMD patients with different pain locations. Int $\mathrm{J}$ Prosthodont. 2017;30(3):251-7.

17. Dworkin SF, Leresche L. Research diagnostic criteria for temporomandibular disorders: review, criteria, examinations and specifications, critique. J Craniomandib Disord. 1992;6(4):301-55.

18. Pereira Júnior FJ. Critérios de diagnóstico para a pesquisa das disfunções temporomandibulares (RDC/TDM): tradução oficial para língua portuguesa. JBC J Bras Clin Odontol Integr. 2004;8(47):384-95.

19. Jensen MP, Karoly P, Braver S. The measurement of clinical pain intensity: a comparison of six methods. Pain. 1986;27(1):117-26.

20. Buysse D, Reynolds CF, Monk TH. The Pittsburgh Sleep Quality Index: a new instrument for psychiatric practice and research. J Psychiatr Res. 1989;8(2):193-213.

21. Bertolazi NA. Tradução, adaptação cultural e validação de dois instrumentos de avaliação do sono: Escala de Sonolência de Epworth e Índice de Qualidade de Sono de Pittsburgh [Dissertação]. Porto Alegre (RS): Universidade Federal do Rio Grande do Sul; 2008.

22. Marcolino J. Escala hospitalar de ansiedade e depress. Rev Bras Anestesiol. 2007;57(1):25-34.

23. Minghelli B, Kiselova L, Pereira C. Associação entre os sintomas da disfunção temporo-mandibular com factores psicológicos e alterações na coluna cervical em alunos da Escola Superior de Saúde Jean Piaget do Algarve. Rev Port Saude Publica. 2011;29(2):140-7.

24. Ferreira CL, da Silva MA, Felício CM. Signs and symptoms of temporomandibular disorders in women and men. CoDAS. 2016;28(1):17-21.

25. Moreira Mello MV. Disfunção temporomandibular e fatores associados em trabalhadores da indústria 
[Dissertação]. Salvador (BA): Universidade Federal da Bahia; 2014.

26. Clark WC, Yang JC, Tsui SL, Ng KF, Clark BC. Unidimensional pain rating scales: a multidimensional affect and pain survey (MAPS) analysis of what they really measure. Pain. 2002;98(3):241-7.

27. Campi LB. Avaliação de alodínia e hiperalgesia cefálica e extracefálica associadas às disfunções temporomandibulares dolorosas [Dissertação]. Araraquara (SP): Universidade Estadual Paulista Julio de Mesquita Filho - UNESP, Faculdade de Odontologia de Araraquara; 2015.

28. Wiwckiewicz W, Wofniak K, Pidtkowska D, Szyszka-Sommerfeld L, Lipski M. The diagnostic value of pressure algometry for temporomandibular disorders. Biomed Res Int. 2015;2015:1-8. Doi $10.1155 / 2015 / 575038$.

29. Correia LM, Guimarães ML, Teixeira ML, Rodrigues LL. Evaluation of body painful areas in patients with muscular temporomandibular disorder: a retrospective study. Revista Dor. 2015;16(4):249-53.

30. Franco AL, Oliveira CB, Fernandes G, Castanharo SM, de Godói DA, Camparis CM. Sensibilidad dolorosa a la palpación en pacientes con disfunción temporomandibular crónica. Rev Cubana Estomatol. 2009;48(4):352-62.

31. La Touche R, Paris-Alemany A, Hidalgo-Pérez A, López-de-Uralde-Villanueva I, Angulo-DiazParreño S, Muñoz-García D. Evidence for central sensitization in patients with temporomandibular disorders: a systematic review and meta-analysis of observational studies. Pain Pract. 2018;18(3):388-409.

32. Glaros AG. Temporomandibular disorders and facial pain: a psychophysiological perspective. Appl Psychophysiol Biofeedback. 2008;33(3):161-71.

33. Kindler S, Samietz S, Houshmand M, Grabe HJ, Bernhardt O, Biffar R et al. Depressive and anxiety symptoms as risk factors for temporomandibular joint pain: a prospective cohort study in the general population. J Pain. 2012;13(12):1188-97.

34. Monteiro DR, Zuim PR, Pesqueira AA, Ribeiro PP, Garcia AR. Relationship between anxiety and chronic orofacial pain of temporomandibular disorder in a group of university students. J Prosthodont Res. 2011;55(3):154-8.

35. Pozzebon D, Piccin CF, Silva AM, Corrêa EC. Temporomandibular dysfunction and craniocervical pain in professionals of the nursing area under work stress. Rev. CEFAC. 2016;18(2):439-48.

36. Chisnoiu AM, Picos AM, Popa S, Chisnoiu PD, Lascu L, Picos A et al. Factors involved in the etiology of temporomandibular disorders - a literature review. Clujul Med. 2015;88(4):473.

37. Soares M, Rizzatti-Barbosa CM. Chronicity factors of temporomandibular disorders: a critical review of the literature. Braz Oral Res. 2015;29(1):1-6.

38. Luro PR. A importância da qualidade do sono na disfunção temporomandibular: estudo piloto [Dissertação]. Beira (Portugal): Universidade Católica Portuguesa, Centro Regional das Beiras, Departamento de Ciências da Saúde; 2011.

39. Edwards Fillingim RB. Self-reported pain sensitivity: lack of correlation with pain threshold and tolerance. Eur J Pain. 2007;11(5):594-8.

40. Bezerra BP, Ribeiro Al, Farias AB, Farias AB, Fontes LB, Nascimento SR et al. Prevalência da disfunção temporomandibular e de diferentes níveis de ansiedade em estudantes universitários. Rev Dor. 2012;13(3):235-42. 